Etnográfica

Revista do Centro em Rede de Investigação em

Antropologia

vol. 20 (3) | 2016

Vol. 20 (3)

\title{
Milongas barriales en la ciudad de Buenos Aires: sentidos de lugar, sociabilidad y tradiciones
}

Milongas in the neighborhoods of the city of Buenos Aires: sense of place, socializing and tradition

\section{Hernán Morel}

\section{(2) OpenEdition}

\section{Journals}

Edición electrónica

URL: https://journals.openedition.org/etnografica/4648

DOI: $10.4000 /$ etnografica.4648

ISSN: 2182-2891

\section{Editor}

Centro em Rede de Investigação em Antropologia

\section{Edición impresa}

Fecha de publicación: 1 octubre 2016

Paginación: 517-538

ISSN: 0873-6561

\section{Referencia electrónica}

Hernán Morel, «Milongas barriales en la ciudad de Buenos Aires: sentidos de lugar, sociabilidad y tradiciones», Etnográfica [En línea], vol. 20 (3) | 2016, Publicado el 28 noviembre 2016, consultado el 09 febrero 2022. URL: http://journals.openedition.org/etnografica/4648 ; DOI: https://doi.org/10.4000/ etnografica. 4648

\section{(c) (;) (9)}

Etnográfica is licensed under a Creative Commons Attribution-NonCommercial 4.0 International License. 


\section{Milongas barriales en la ciudad de Buenos Aires: sentidos de lugar, sociabilidad y tradiciones}

\section{Hernán Morel}

A partir de una investigación etnográfica centrada en cuatro milongas que se realizan en clubes barriales ubicados en el noroeste de la ciudad de Buenos Aires, en este artículo reflexionamos sobre los sentidos de lugar que construyen los participantes y organizadores de estos eventos. El análisis incluye tanto las narrativas que entrelazan a estos lugares con diferentes tradiciones y referencias al pasado, como las dinámicas de encuentro y sociabilidad que se despliegan dentro de estos eventos de danza. Específicamente indagamos estos aspectos a partir de las semejanzas y diferencias que se establecen entre aquellas milongas que se consideran más antiguas y tradicionales, frente a la aparición de algunas "nuevas milongas" que se ubican en la misma zona. A través de este análisis argumentamos que los sentidos de lugar, los modos de sociabilidad y las referencias al pasado que construyen las personas y grupos que participan de estas milongas no son necesariamente unívocos, del mismo modo que tampoco son inmunes a procesos de reconfiguración y cambio.

PALABRAS-CLAVE: milongas, eventos de danza, sentidos de lugar, tradiciones, sociabilidad.

Milongas in the neighborhoods of the city of Buenos Aires: sense of place, socializing and tradition - In this article we will reflect on the sense of place that is developed by the participants and organizers of "milongas". This analysis is based on some ethnographic research conducted on four milongas that take place at local clubs in some neighborhoods from the northwest of the city of Buenos Aires. This analysis not only includes narrations that relate these dancing places with different traditions and references to the past, but also the dynamics of meeting and socializing that occur in these dancing events. We pay special attention to these aspects through the differences and similarities established between those milongas that have taken place for longer periods and which are considered more traditional, and the "new milongas" that take place around the same area. Moreover, based on this analysis, we claim that the sense of place, the form of socialization and the references to the past which are developed by the groups and the people that participate in these milongas are not necessarily univocal and that they are not immune to changing processes and reconfiguration.

KEYWORDS: milongas, dancing events, sense of place, tradition, socializing.

MOREL, Hernán (hermorel@hotmail.com) - Conicet, ICA-UBA, Argentina. 


\section{INTRODUCCIÓN}

Un mapeo realizado en 2015 por el Gobierno de la Ciudad Autónoma de Buenos Aires indicaba que en la ciudad existen más de 100 lugares en donde las personas a diario se reúnen para bailar tango. ${ }^{1}$ Estos lugares de baile, conocidos como "milongas", comúnmente se emplazan en salones, confiterías, clubes sociales y deportivos, sociedades de fomento, centros culturales, así como existen algunas que se organizan en espacios al aire libre como en plazas y parques públicos. Señalemos que en las últimas décadas la cantidad de milongas, así como la actividad en torno a las mismas, ha tenido un importante crecimiento, del mismo modo que se han diversificado considerablemente estos lugares de baile. ${ }^{2}$

Acompañando este proceso de expansión del fenómeno de las milongas, distintas investigaciones recientes se han enfocado en el análisis de estos lugares bailables, advirtiendo las dinámicas de sociabilidad y de comportamiento singulares que caracterizan a estos eventos de danza. ${ }^{3}$ En especial varias autoras a nivel local han estudiado distintos aspectos del fenómeno, los cuales incluyen entre otros las construcciones de femineidad que se despliegan hacia el interior de las milongas porteñas (Savigliano 2002), los saberes y los movimientos de baile que operan en las milongas del circuito céntrico (Carozzi 2015), o las modificaciones que introducen en esta danza las milongas queer y del "tango nuevo" (Cecconi 2009; Liska 2009; Ramos 2008/2010; Lucio y Montenegro 2012).

A partir de una investigación etnográfica centrada en cuatro milongas que se realizan en clubes barriales ubicados en el noroeste de la ciudad de Buenos Aires (el Sin Rumbo, el Sunderland, el Morán y el Ciencia y Labor), el presente artículo pretende analizar los diferentes modos a través de los cuales los participantes y organizadores de estas milongas construyen sentidos de lugar, tradiciones y formas de sociabilidad (ver figura 1 ). ${ }^{4}$

l Dicho mapeo fue realizado conjuntamente con la Asociación de Organizadores de Milongas, ver $<$ http://tangoypatrimonio.com.ar/wp-content/uploads/2014/02/folleto-milongas_2015.pdf > (consultado el 10 de septiembre de 2015).

2 Recordemos que a partir de los años 60, luego de las llamadas "décadas de oro del tango" del 40 y el 50 - período en que el género alcanzó su máxima difusión -, las milongas porteñas dejaron de tener el protagonismo y la afluencia de público de las décadas anteriores, reduciéndose como ámbitos de incorporación para las nuevas generaciones, situación que se fue revirtiendo de manera gradual a partir de la década del 80, tras el fin de la última dictadura militar (Morel 2012).

3 La antropóloga María Julia Carozzi (2015) propuso designar a estos lugares de reunión en donde se baila el tango social "eventos de danza".

4 En lo que concierne a la investigación de campo inicie mi inmersión en el mundo de las milongas de Buenos Aires a partir de mi pesquisa de doctorado. En parte, utilizo aquí materiales de esta investigación recolectados entre el 2006 y el 201 l. A su vez, otras fuentes de información sobre la que se basa este artículo provienen de mis experiencias de observación y participación derivadas de un proyecto de investigación actual que aborda a las milongas que se organizan en clubes barriales de la [continua] 


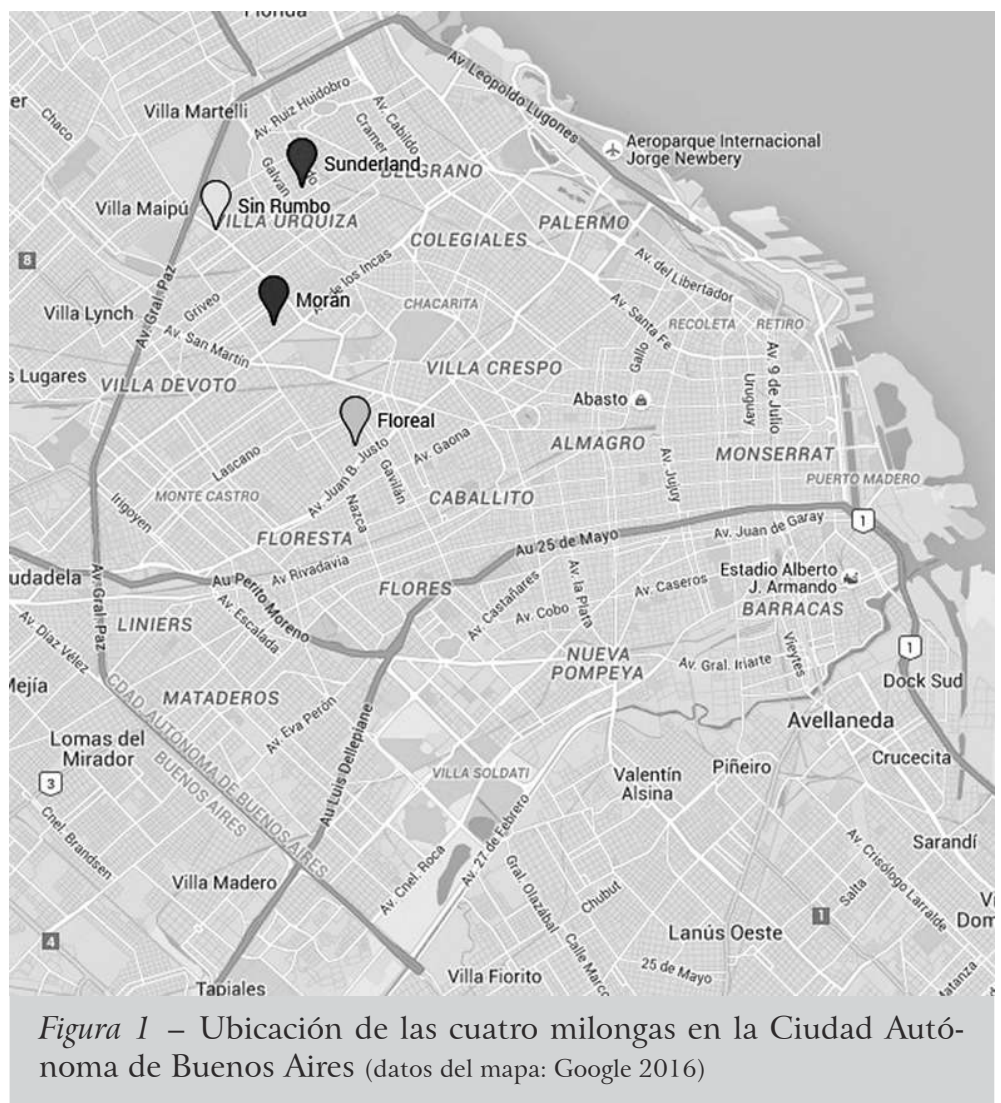

Un motivo importante por el que restringimos nuestra etnografía a las milongas ubicadas en esta zona de la ciudad proviene del hecho de que estos lugares suelen ser considerados por los milongueros y milongueras como ámbitos de baile bastante "tradicionales". ${ }^{5}$ De manera que a partir de los casos analizados describimos las narrativas y prácticas que entrelazan a estos lugares con diferentes memorias, tradiciones y pautas provenientes del pasado, las cuales, como veremos, permiten acentuar determinados "códigos” de comportamiento y formas de sociabilidad en desmedro de otros

zona del noroeste de la ciudad. Dicho trabajo de campo incluyó, además de mi participación en eventos culturales específicos - sea tomando clases o yendo a bailar a distintas prácticas y milongas -, la realización de entrevistas semi-estructuradas y conversaciones informales con distintos participantes asiduos y organizadores de estas milongas. Estos materiales recolectados se complementan con otras fuentes de información provenientes de noticias y crónicas suministradas por medios de prensa y redes electrónicas de comunicación.

5 "Milongueros" y "milongueras" son términos emic. Esta denominación la utilizan los participantes de las milongas para referirse a las personas que son asiduas concurrentes a estos eventos. 
posibles. ${ }^{6}$ Por tanto, desde una perspectiva atenta a las dinámicas de autoridad y las estrategias de legitimación que organizan a estos lugares, advertimos las narrativas y las prácticas variables que allí se despliegan, problematizando los múltiples significados que el pasado de estos lugares tiene para los diferentes agentes que organizan y asisten a estos eventos. En este sentido, entendemos a la tradición como una construcción simbólica selectiva, un proceso de reelaboración e invención permanente que supone la ratificación de un presente a partir de conexiones significativas que se establecen con elementos del pasado (Williams 2000 [1977]; Bauman 2000; Martín 2005). Del mismo modo, tal como observó Sahlins (2004), consideramos que las tradiciones también están constituidas por aspectos creativos o inventivos, en ocasiones a partir de las diferentes significaciones que adquieren éstas en relación a nuevos contextos y situaciones socioculturales.

Además, sugeriremos que las personas y grupos que asisten a las milongas que se consideran más tradicionales, no solo legitiman su predominio dentro estos ámbitos a partir de las referencias activas que establecen con un pasado significativo, sino que tal como reveló Elias (2000 [1994]) en su trabajo "Ensayo teórico sobre las relaciones establecidos-outsiders",

"Ali, podia-se ver que a 'antiguidade' da associação, com tudo o que ela implicava, conseguia, por si só, criar o grau de coesão grupal, a identificação coletiva e as normas comuns capazes de induzir à euforia gratificante que acompanha a consciência de pertencer a um grupo de valor superior, com o desprezo complementar por outros grupos" (Elias 2000 [1994]: 21).

Por lo cual, como expondremos aquí, los asistentes más antiguos y establecidos de algunas de estas milongas consiguen imponer más fácilmente dentro de estos lugares un conjunto de normas y valores que los ubican en posiciones de prestigio y de poder, de manera tal que tienden a excluir a aquellas personas y grupos más recientes, aquellos que no forman parte de sus círculos de sociabilidad o que no respetan ciertos códigos de comportamiento.

En términos metodológicos, en este trabajo haremos uso de la comparación como herramienta de análisis para los datos etnográficos (Peirano 1995; Bourdieu y Wacquant 1995; Barth 2000). Tal como señala Barth, "debemos usar lo más activamente posible comparaciones en el análisis de cada caso específico" (2000: 200, nuestra traducción), por un lado, como solución a la reificación de nuestras descripciones de los objetos comparados y, por otro, en la búsqueda

6 Como se verá más adelante en este artículo, la noción de "códigos" es una categoría nativa que busca regular las normas de convivencia y los comportamientos admitidos dentro de la milonga. Entre otros, estos "códigos" hacen referencia a la manera en que se viste, el modo en que se invita a bailar, el modo en que se baila o cómo se mueven las parejas dentro del espacio de la pista de baile. 
de variabilidad de los datos primarios obtenidos en el campo etnográfico. En particular, me propongo analizar las semejanzas y diferencias que se establecen entre aquellas milongas que suelen considerarse como "tradicionales", frente a la aparición de algunas "nuevas milongas", las cuales, sin embargo, buscan formar parte de este circuito de baile tradicional de la zona. Por último, argumentaremos que los sentidos de lugar, los modos de sociabilidad y las referencias al pasado que se producen en estas milongas barriales no son necesariamente unívocos, del mismo modo que tampoco son inmunes a procesos de reconfiguración y cambio.

\section{LA ANTROPOLOGÍA Y LOS LUGARES}

Podríamos afirmar que la noción de lugar en los estudios clásicos de la antropología ha tenido un papel bastante destacado, si bien también ha estado cargada de ambivalencias y de puntos oscuros. No sin desacuerdos y a través de distintas vertientes teóricas, la antropología ha contribuido al análisis de la dimensión territorial de la vida social preocupándose por los significados que le atribuyen las comunidades locales a los espacios y lugares en que viven. Como sostiene Trajano Filho (2012), la tradición disciplinar desplegó un amplio campo semántico ligado a las nociones de espacio, lugar, territorio y paisaje. ${ }^{7}$

Señalemos que en las últimas décadas estas nociones han evidenciado una significativa revitalización, a partir de un nuevo escenario mundial en el que se intensifican las interconexiones, los movimientos y los flujos globales, hecho que trajo aparejado una revisión del concepto de cultura y de lugar. A partir de ello, entre otras críticas, algunos autores han planteado el hecho de que con demasiada frecuencia la tradición antropológica concibió al concepto de cultura en una localización espacial demasiado delimitada, unificada e internamente homogénea (Augé 1993: 40). Como sostienen Gupta y Ferguson, la "tendencia a localizar implícitamente las culturas en determinados lugares suscita otra serie de problemas en torno a la cuestión de cómo explicar las diferencias culturales dentro de una misma localidad" (Gupta y Ferguson 2008: 236).

El planteo de una asociación naturalizada entre cultura y lugar ha impedido problematizar los múltiples y diversos sentidos que las personas y los grupos le otorgan a los lugares, tomándolos como dados y no como el producto de una

7 Según este autor, el interés por estas nociones abarca los planteos evolucionistas de Morgan y Maine que intentaban explicar la transición de una sociedad gentilicia a una sociedad política con base territorial; los análisis estructural-funcionalistas de Evans-Pritchard que abordaban la estructura territorial y ecológica en relación a la estructura política; la vertiente culturalista norteamericana de Boas, que examinó los sistema de nombres indígenas en relación a la organización del ambiente físico; las investigaciones de Durkheim y Mauss, vinculadas a los sistemas de clasificación social del espacio y el territorio; así como los aportes de Lévi-Strauss, que procuraron correlacionar las formas de clasificación del espacio con la estructura social (Trajano Filho 2012: 8-11). 
construcción social históricamente situada (Trajano Filho 2012: 8). En efecto, los estudios actuales proponen abordar al concepto de lugar, más que como un dato a priori, como una instancia referida a relaciones sociales que lo producen, relaciones que están atravesadas por múltiples construcciones de sentido, sociabilidades, narrativas, prácticas performativas y ejercicios de poder. Siguiendo esta línea, autores como Cresswell (2004) afirman que necesitamos etnografiar y conocer la forma en que las personas y los grupos sociales cargan a los lugares de significado y construyen saberes locales a través de prácticas discursivas y performativas que le otorgan un "sentido de lugar" sobre la base de historias, sucesos, elementos afectivos y memorias localizadas.

Por otra parte, algunos autores brasileños han contribuido al análisis de estos temas destacando la interdependencia que opera entre los lugares y los sentimientos de pertenencia, señalando los lazos estrechos que conectan a los lugares con las personas y los grupos sociales (Trajano Filho 2012; Gonçalves 2013). ${ }^{8}$ Asimismo, estas aproximaciones advierten los modos en que los lugares son construidos e imaginados a través de la actividad narrativa, sosteniendo que:

“... a constituição dos lugares é uma atividade central na construção das narrativas que enquadram o passado, o presente e o futuro. Nossa história, o nosso mundo do aqui e agora e o devir que projetamos para nós e para os outros estão irremediavelmente associados aos lugares que lembramos e criamos. Em outras palavras, muito do que somos são os lugares que imaginamos" (Trajano Filho 2012: 7).

De acuerdo a este autor, las narrativas que constituyen a los lugares están siempre conformadas por un atributo temporal. Parafraseando a Ochs (2000 [1997]), podríamos afirmar que cuando elaboramos narraciones que refieren al pasado, lo hacemos en términos de lo que ellas implican tanto para el presente como para el futuro. En otras palabras, las narrativas que muchas veces las personas y los grupos construyen para recordar el pasado, en este caso de determinados lugares, están estrechamente relacionadas con el interjuego de circunstancias presentes y las expectativas futuras (Jelin 2001). Tal como lo han observado otros autores, esta dinámica narrativa también puede ser concebida como un proceso de tradicionalización, en tanto prácticas que suponen el ejercicio de referencias activas a un pasado significativo que se legitima en el presente (Bauman 2000; Martín 2005).

8 Trajano Filho (2012) observa que, si bien en las últimas décadas se han incrementado los estudios que abordan los desplazamientos y flujos globales a través del territorio, al mismo tiempo emergen pesquisas que dan cuenta de mundos cada vez más localizados en los que se reivindican sentimientos de pertenencia estrechamente enlazados con ciertos lugares. 


\section{ACERCA DE LAS MILONGAS Y LOS CIRCUITOS MILONGUEROS EN BUENOS AIRES}

Las personas que van a bailar tango social de manera asidua o con cierta frecuencia suelen referirse a la milonga apelando al nombre de la misma, al lugar físico en que se emplaza, o simplemente mencionando el día y el horario en que funciona. Si bien la gran mayoría de las milongas se organizan un día a la semana, existen algunas que funcionan una vez al mes. Su horario suele ser nocturno, aunque también están aquellas que funcionan más temprano en horarios por la tarde o de matiné. Para ingresar a las milongas se paga una entrada, aunque también hay algunas que tienen entrada gratuita o "a la gorra". Hay milongas con capacidad para pocas parejas y otras en las que llegan a caber más de 400 personas. En términos etarios, las personas que concurren a estos lugares, dependiendo del tipo de milonga, abarcan una franja que va desde los 15 a los 80 años; suelen haber sujetos de distintos estratos sociales, con variados oficios y profesiones, entremezclados con personas de diversas procedencias nacionales. Desde el punto de vista de la población porteña, en general podríamos decir que predominan sectores de clase media, entre los que se encuentran trabajadores manuales, pequeños comerciantes, empleados, jubilados, profesionales, pequeños empresarios, estudiantes universitarios y artistas. También es común que asistan a las milongas porteñas turistas y extranjeros provenientes en mayor medida de países europeos, latinoamericanos, de Japón o de Estados Unidos.

Un representante importante en la gestión de todo lo necesario para el funcionamiento de una milonga es el "organizador/a", figura que se encarga de convocar al público asistente y que coordina todo el desarrollo del evento. Los organizadores pueden estar representados por una o más personas y, en cierto modo, son los "pequeños empresarios" del evento. Destaquemos que el organizador es el encargado de articular a todos los actores que participan de la milonga: el musicalizador/a, el profesor/a que da clase, los bailarines que brindan una exhibición, los músicos, el buffet, del mismo modo que se encarga de toda la infraestructura necesaria para que el evento se lleve a cabo. A su vez, el organizador cumple también el rol de "anfitrión": su labor no consiste solo en convocar a los asistentes a través de la difusión y la publicidad sino que establecen un trato permanente y personalizado con la gente que asiste a su milonga. ${ }^{9}$ Como veremos, el hecho de que los organizadores/as sean también milongueros/as implica que su impronta personal influya mucho en las pautas

9 En líneas generales, los medios a través de los cuales las milongas se publicitan a sí mismas incluyen desde la entrega de "volantes" dentro de otras milongas hasta la difusión a través de la publicidad en distintas revistas de tango. A su vez, en los últimos años adquirió mayor importancia la difusión a través de Internet y de las redes sociales virtuales. 
de sociabilidad y los códigos de comportamiento que se despliegan dentro de los eventos que organizan.

Por lo general, en las milongas de Buenos Aires podemos identificar distintos circuitos milongueros. Cuando nos referimos a que existen circuitos milongueros aludimos a que las personas que van a bailar el tango social de manera asidua lo hacen estableciendo un itinerario más o menos recurrente por determinados lugares de baile, en ocasiones transformándose en habitués de los mismos. Entre otras razones, estos circuitos suelen estar guiados por determinadas disposiciones, gustos, intereses y expectativas a partir de los cuales las personas prefieren ir a bailar a determinados lugares y no a otros. Estas razones, por mencionar solo algunas, pueden relacionarse con: los vínculos de amistad que allí se generan, el tipo de ambiente de la milonga (ligado con la música que pasan, la distribución del espacio, la iluminación, etc.), con el nivel de baile, con los "códigos" que allí se manejan, con el tipo de movilidad y desplazamiento que se da en la pista, con las características de las personas que concurren (vinculadas con el tipo de edad, las orientaciones sexuales, la presencia o no de turistas, etc.), con la proximidad de sus lugares de residencia, entre otros aspectos.

Por su parte, una primera distinción que establece Carozzi (2015) entre los circuitos de milongas de Buenos Aires que funcionaban durante la década del 2000 consiste en diferenciar a las milongas "ortodoxas" de otro circuito alternativo que los propios concurrentes definieron como milongas "relajadas" o "prácticas". ${ }^{10}$ Según la autora, las milongas ortodoxas designan aquellos eventos de danza que están estrictamente regulados por determinados "códigos" de comportamiento, de relacionarse y de bailar. Estos códigos, defendidos con mayor frecuencia por los milongueros mayores, regulan la disposición y distribución de las personas dentro del espacio de la milonga, las formas de vestir, los modos de invitar a bailar, la manera en que se dirige y se abandona la pista, los estilos de baile o la movilidad que se da dentro del espacio de la pista. ${ }^{11}$ A diferencia de estos eventos con prácticas altamente ritualizadas, en las denominadas milongas relajadas, también identificadas como milongas frecuentadas en mayor medida por gente "joven", algunos de estos "códigos" tienden a ser transgredidos, de modo que en estas milongas se advierten "diferentes" y "nuevas" formas de baile, de relacionarse y de comportarse. Entre otras prácticas que desafían las disposiciones de los antiguos milongueros, en estos eventos se observan modos de vestir más cotidianos o con un menor grado de formalidad, del mismo modo que también es posible el baile de parejas del mismo sexo.

10 Por "práctica" de tango nos referimos a un evento que se organiza para que las personas entrenen, ensayen, investiguen y/o intercambien ideas sobre el baile, en algunos casos con la asistencia de profesores. Estos encuentros no necesariamente cumplen con los distintos códigos de comportamiento que se acostumbran en las denominadas milongas.

I I Para un análisis pormenorizado de estos "códigos", ver Carozzi (2015: 121). 
Por nuestra parte, el circuito de milongas que analizamos en este trabajo es evaluado en términos nativos como un circuito de milongas "tradicionales" o "barriales" y, en cierto modo, estas milongas coinciden en muchos aspectos con las denominadas "ortodoxas". Con todo, en este artículo argumentaremos que los sentidos de lugar, los modos de sociabilidad y las referencias al pasado que se producen en estas milongas barriales presentan algunas variaciones entre sí, por lo que estos sentidos y prácticas no son necesariamente unívocos del mismo modo que tampoco son inmunes a procesos de reconfiguración y cambio. Teniendo en cuenta esto, a continuación me propongo explorar de qué modo los organizadores y participantes involucrados en estos circuitos de baile del noroeste de la ciudad elaboran y ponen en juego, tanto de manera cooperativa como conflictiva, distintos usos y sentidos asociados a estos lugares.

\section{LAS MILONGAS EN LOS CLUBES DE BARRIO: EL SIN RUMBO Y EL SUNDERLAND}

Según suelen contar los milongueros más antiguos, en los barrios de la zona del noroeste de la ciudad - un área que abarca en líneas generales a Villa Urquiza, Saavedra, Villa Ortúzar, Villa Pueyrredón, Agronomía, Villa Devoto y Paternal funcionaron durante las famosas décadas del 40 y el 50 muchos clubes sociales y deportivos en los que se organizaban bailes de tango de manera periódica (Pujol 1999). ${ }^{12}$ En la actualidad en esta zona, existen algunos pocos clubes barriales que continúan organizando bailes de tango, dentro de los cuales se destacan y mencionan con mayor frecuencia dos de ellos que se ubican en el barrio de Villa Urquiza: el Club Social y Deportivo Sin Rumbo y el Sunderland Club. ${ }^{13} \mathrm{Al}$ menos desde que comencé mi investigación en el año 2006, estos clubes realizan bailes de tango de manera ininterrumpida cada semana, el primero los días viernes y el segundo los días sábados, siempre en horario nocturno. Estos eventos se organizan, en el caso del Sin Rumbo en un salón (con una capacidad aproximada de 150 personas), mientras que para la realización

12 En lo que refiere a los cuatro clubes barriales que analizamos en este artículo, todos ellos fueron fundados en las primeras décadas del siglo XX. Según suele mencionase, en el apogeo de la "época de oro" del tango, allí se realizaban bailes muy populares y masivos en donde además de que se bailaba tango, así como otras músicas como foxtrot, jazz, swing o tropical, también actuaban las "grandes" orquestas típicas de entonces. Con el paso del tiempo, durante las décadas del 60 y el 70 estos clubes fueron dejando de realizar bailes, aunque en algunos casos puntuales se siguió organizando bailes de manera esporádica. En los 80 y principios de los 90, poco a poco se fue reactivando la actividad milonguera, cuando algunos clubes comenzaron nuevamente a organizar bailes de manera periódica. En especial, como veremos, el Sin Rumbo fue un espacio de encuentro importante para los milongueros y milongueras locales durante la década del 80 , seguido en los 90 por la milonga que se realiza en el Sunderland.

13 El primero se ubica en la calle Tamborini $6157 \mathrm{y}$ el segundo en Lugones 3161. 
de la milonga del Sunderland se utiliza una cancha de básquet (en la que caben alrededor de 400 personas).

Quienes se encargan de organizar la milonga en estos clubes suelen ser parejas de milongueros (marido y mujer) mayores de 60 años, los cuales son coloquialmente identificados por el apellido de la familia (los Matera, los Dupáa, los Rodríguez), aunque en los últimos años en el Sin Rumbo han comenzado a colaborar en la organización algunos milongueros/as de edad intermedia. Mencionemos que la mayor parte del público que asiste a estos lugares - en muchos casos desde hace considerables años - es gente de edad intermedia y avanzada, y tan solo en los últimos años se observa una mayor afluencia y cantidad de jóvenes participando. En efecto, como veremos a continuación, las pautas de sociabilidad y de actuación que tienden a primar en estas milongas barriales están fuertemente regidas por la autoridad, la opinión y los puntos de vista de los milongueros más antiguos y establecidos.

Por su parte, la milonga del Club Sin Rumbo, tal como lo celebra un cartel en la entrada a su salón, es también conocida por el nombre de "La catedral del tango". En particular, dentro del ámbito milonguero porteño, el Sin Rumbo es identificado como un club con mucha "historia de tango", un lugar que se distingue de las demás milongas porteñas por haber sido frecuentado por "legendarios" milongueros. En relación a ello, una nota periodística señala:

"Quienes hoy se acercan al tango, a poco de andar en él se topan con la mítica fama del Sin Rumbo. Detrás del sobresalto metafísico que provoca el nombre se esconde un pasado de leyendas y aventuras. 'La historia cuenta que acá venían a probarse los grandes milongueros - dice Dupláa [milonguero y organizador]. De a poco se armó la fama de que se bailaba bien en el Sin Rumbo y por eso se llenaba, y eso que Villa Urquiza era el fin del mundo. Era un lugar de prestigio pero también de vanguardia'. No hay milonguero de ley que no haya brillado en la pista de damero del Sin Rumbo; por allí pasaron todos aquellos que delinearon el tango que conocemos hoy en día. Por cierto, salir al ruedo en ese damero no era para cualquiera: 'Era medio difícil bailar acá. Una vez Olivetto, que era el que organizaba, paró en la puerta a uno que pispeaba para entrar y le preguntó si bailaba. Más o menos, contestó el tipo. Entonces no saque la entrada, le dijo; acá los que bailan más o menos no entran'. [...] El Club Sin Rumbo cumplió 90 años y luce tan coqueto y jovial que hasta tiene sitio web. Conserva su merecida fama de 'lugar de buen bailar' pero se han sosegado los egos de otras épocas y es hoy un ámbito familiar que recibe cálidamente a visitantes y habitués". ${ }^{14}$

14 Publicado en <http://www.revistaenie.clarin.com/escenarios/Club-Sin-Rumbo-La-milonga-masantigua-del-mundo_0_634136794.html > (última consulta en octubre del 2016). 
Vemos de qué manera a través de esta narrativa se connota al lugar y el nombre del Sin Rumbo en estrecha asociación a los "milongueros de ley" que concurrían al mismo. En efecto, la exaltación de estos "grandes milongueros", la memoria "legendaria" de sus historias y su identificación primordial con el lugar permite construir una versión del pasado a través de la cual se legitima a este club barrial como un lugar "famoso", único y emblemático por su "buen bailar", hecho que, a su vez, dota de una especie de "carisma grupal" a las personas y grupos que participan regularmente de estos ámbitos sociales. ${ }^{15}$ Por su parte, este carisma grupal presume "una virtud específica que es compartida por todos sus miembros y de la cual carecen los otros" (Elias 2000 [1994]: 20, nuestra traducción).

A su vez, en las últimas décadas tanto el Sin Rumbo como el Sunderland han ido adquiriendo una gran fama internacional, en mayor grado el segundo, el cual es reconocido y publicitado como "La milonga del mundo". A pesar de que ambas milongas están ubicadas en una zona periférica bastante alejada del centro de la ciudad, frecuentemente son visitadas por turistas extranjeros y milongueros/as de distintas partes del mundo. ${ }^{16} \mathrm{~A}$ ello se suma los bailarines argentinos que constantemente viajan, hacen giras o que residen en el extranjero, los cuales también suelen "retornar" permanentemente a estos lugares emblemáticos. ${ }^{17}$ Señalemos además que estas milongas tradicionales, para muchos bailarines profesionales y profesores de tango, son ámbitos significativos para mostrarse y revalidarse ante los demás, en vistas a que exponerse en estos lugares prestigiosos les confiere cierto capital simbólico y

15 Esta narrativa construida en torno a los milongueros y las milongas de Villa Urquiza también es reafirmada a través distintos ámbitos oficiales. Para el caso el barrio de Villa Urquiza, ha sido declarada por la legislatura de la ciudad como la "capital del tango bailado" en el año 2011. Además, tanto la milonga del Sin Rumbo como la del Sunderland fueron seleccionadas para formar parte del inventario de seis milongas que realizó durante el año 2013 la UNESCO, con el propósito de promover la salvaguardia de elementos vinculados a las milongas "tradicionales" de Buenos Aires. A su vez, como hemos analizado en otros artículos (Morel 2011), el estilo de baile que algunos denominan Villa Urquiza suele ser una referencia común en muchos de los competidores que participan de los campeonatos de baile que organiza el gobierno de la ciudad de Buenos Aires. Mencionemos que para determinados milongueros el así llamado "estilo Villa Urquiza" posee patrones de forma y repertorios de movimientos que lo distinguen de otras modalidades de baile. A pesar de que existen muchas controversias en torno a los rasgos "típicos", este estilo se lo reafirma como una forma de baile en la que adquiere importancia el hecho de "llevar el compás" y "mantener la elegancia" en el baile. A esto se agregan otros elementos que suelen ser nombrados para caracterizarlo, mencionándose una mayor disposición a la ejecución de "pasos largos", presencia de momentos de pausa, prolijidad en la colocación y el movimiento de los pies, utilización de muchos giros acompañados de figuras y secuencias complejas.

16 Con respecto a esta valoración que se tiene desde el extranjero, en ocasiones las personas que asisten a estas milongas suelen mencionar el hecho de que fueron visitadas por distintos músicos reconocidos y actores de cine internacionales.

17 Como afirma Augé, en cierto modo "El retorno al lugar es el recurso de aquel que frecuenta los no lugares (y que sueña, por ejemplo, con una residencia secundaria arraigada en las profundidades del terruño). Lugares y no lugares se oponen (o se atraen)..." (1993: 110). 
reconocimiento. Por lo pronto, veamos la caracterización que realiza del Sunderland una cronista:

"Fui el sábado pasado y siempre se trata de una experiencia singular. Primero porque queda, para mí, del otro lado del planeta, en el barrio de Villa Urquiza, e ir hasta allá siempre es una odisea. Luego, porque lo más probable es que no baile en toda la noche. Y porque, extrañamente, siempre la paso bien. Se trata, entonces, de un club del barrio de Villa Urquiza que, los sábados, se transforma en milonga, La Milonga del Mundo. Lo gracioso es que la pista está ubicada sobre la cancha de básquet. [...] se trata de una de las milongas más tradicionales de Buenos Aires, allí donde se junta la crème de la crème de los milongueros de ley, y los sobrevivientes de la época de oro del tango. Allí, hasta los más jovencitos hacen un esfuerzo por vestirse bien. Las mujeres sacan a lucir sus más vistosas joyas y sus más infartantes vestidos, los hombres no escatiman en gomina y cuidan cada detalle de sus trajes, desde la corbata hasta el pañuelo en el bolsillo, pasando por los zapatos impecablemente lustrados [...] Se respeta el cabeceo, las mujeres esperan, hermosas y erguidas en sus sillas, que algún caballero fije su vista en ellas. Los hombres rivalizan de galantería y elegancia". ${ }^{18}$

El relato ilustra algunos de los "códigos", los modos de actuación e interacción social que caracterizan al Sunderland. Como vemos, éstos implican, a diferencia de otros circuitos de milongas más "relajadas", determinadas formalidades en cuanto a los modos de invitar a bailar, de comportarse o de vestir, los cuales tienden a ajustarse a las prácticas de sociabilidad y formas de interacción esperadas por las personas y grupos más establecidos.

Dicho esto, ¿cómo se organiza el espacio dentro de estas milongas? ¿De qué manera se distribuyen las personas y los grupos? ¿Cuáles son las dinámicas de interacción y de sociabilidad frecuentes? Algo que caracteriza a estas milongas es que funcionan en ambientes bien iluminados, lo cual facilita el contacto visual entre los asistentes (ver figura 2), del mismo modo que el volumen no muy elevado de la música permite la posibilidad de diálogo entre los presentes. $\mathrm{Al}$ igual que en la mayoría de las milongas de Buenos Aires, la delimitación más notoria dentro del espacio es aquella que separa la pista de baile propiamente del espacio que la rodea, lugar en donde se encuentra ubicada la gente en sus mesas mientras no se halla bailando. En general, los concurrentes habituales a estas milongas siempre se ubican en las mismas mesas. Por su parte, las mesas preferidas suelen ser aquellas que están alrededor de la pista de baile, una ubicación estratégica para invitar o ser invitado/a a bailar o simplemente

18 En <http://enlamilonga.blogspot.com.ar/2008/06/sunderland-club.html >, 2 de julio de 2008 (última consulta en octubre del 2016). 


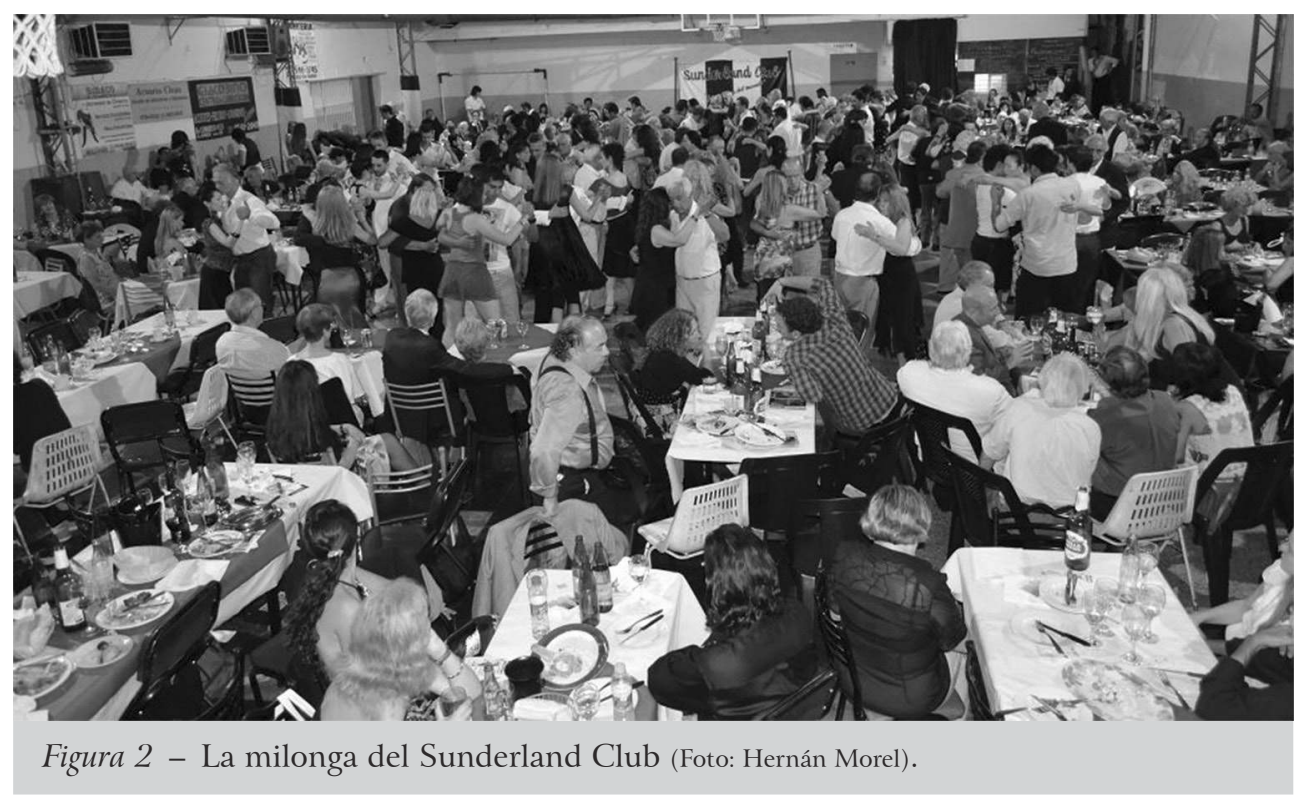

para observar lo que ocurre dentro de la pista. Además, en estas mesas suelen estar los milongueros/as considerados/as con mayor reputación o aquellos/as que son bailarines/as profesionales. En consecuencia, las mesas que están más alejadas de la pista son utilizadas por las personas y grupos que no asisten tan frecuentemente a la milonga.

Algo también característico de estas milongas barriales es que muchos de los asistentes regulares se conocen interpersonalmente, de manera que durante la noche la gente además de bailar despliega una intensa sociabilidad. Así, por ejemplo, cuando las personas ingresan a la milonga y mientras se dirigen a su mesa, es común que vayan saludando a lo largo del recorrido a sus redes de amistad y conocidos. También es común ver grandes mesas con grupos de amigos y amigas, así como se advierte la presencia de bailarines y profesores que comparten la actividad de la noche junto a sus alumnos. En ocasiones, los organizadores de estas milongas también suelen acercarse a las mesas para saludar, conversar o bromear con los presentes. Además, es frecuente que los habitués saluden y se relacionen de manera afectuosa con las personas que trabajan en la milonga, sea el musicalizador, el mozo que los atiende o la persona que se encarga del buffet. ${ }^{19}$ De esta manera, los grupos más antiguos y establecidos (Elias 2000 [1994]) que participan de estos lugares, además de la actividad de la danza propiamente, ejercitan una importante sociabilidad

19 Agreguemos que, además del organizador, otra figura importante que colabora en la realización del evento es el musicalizador. El musicalizador es responsable de las selecciones musicales y del armado de las distintas "tandas", las cuales le imprimen un estilo propio al ambiente de la milonga. 
e interacción verbal con su círculo de conocidos, lo cual también al mismo tiempo les permite mantener posiciones de poder y de prestigio dentro de la milonga.

Sumado a esto subrayemos que, en la mayoría de los casos - aunque existen excepciones -, las personas que concurren a estas milongas lo hacen en pareja o en grupos de amigos, por lo que ser parte o estar vinculado más efímeramente a los círculos de sociabilidad de estos ámbitos facilita el acceso a "invitar" o ser "invitado" a bailar. Tal como lo señala la crónica mencionada más arriba, si alguien va solo o sola a estos lugares, "lo más probable es que no baile en toda la noche" o, al menos, que no le sea tan fácil hacerlo. Esta es una diferencia sustantiva, por ejemplo, con otras milongas de la ciudad - algunas de circuito céntrico - en donde los concurrentes acostumbran asistir en general solos o solas y, por ende, lugares en donde se advierte la expectativa de bailar lo más posible y de hacerlo con diferentes personas, hecho que obliga, en muchos casos, a que las interacciones verbales entre los asistentes tiendan a reducirse (Carozzi 2015: 168).

\section{"NUEVAS MILONGAS" EN LOS CLUBES DE BARRIO: EL MORÁN Y EL FLOREAL}

En la actualidad, además de estas "emblemáticas" milongas que acabamos de describir, existen también algunas "nuevas milongas" en otros clubes de la zona. Si bien muchos consideran a estas milongas como "nuevas", puesto que se han abierto recientemente, señalemos que ya en las famosas décadas del 40 y el 50 allí se organizaban bailes de tango. ${ }^{20}$ De modo que en lo que sigue pretendo realizar una descripción de estas nuevas milongas enfocándome en dos emprendimientos que han emergido en los últimos años. Uno de ellos es la milonga del Morán, la cual funciona desde el año 2009 en el Club Social y Deportivo Morán; la otra es la milonga el Floreal, realizada desde el año 2011 en el Club Ciencia y Labor. ${ }^{21}$ Por su parte, la milonga del Morán se organiza un sábado por mes, mientras que la milonga el Floreal se hace periódicamente todos los domingos por la noche. En lo que refiere al espacio físico, la primera funciona en las instalaciones de un patio techado muy amplio, el cual se usa normalmente como cancha de "papi" futbol, y que a su vez a un costado tiene un pequeño escenario (ver figura 3), mientras que la segunda se efectúa dentro de un salón de medianas dimensiones que posee el club en el primer piso.

20 Cabe resaltar que a diferencia de las milongas del Sin Rumbo y el Sunderland, que organizan bailes de tango desde las décadas del 80 y los 90, las dos milongas que analizamos en este apartado se reactivaron, al menos de manera permanente, hace algunos pocos años.

21 La primera se ubica en la calle Pedro Morán 2446, en el barrio de Agronomía, y la segunda en la calle Cesar Díaz 2453, en el barrio de Villa General Mitre. 


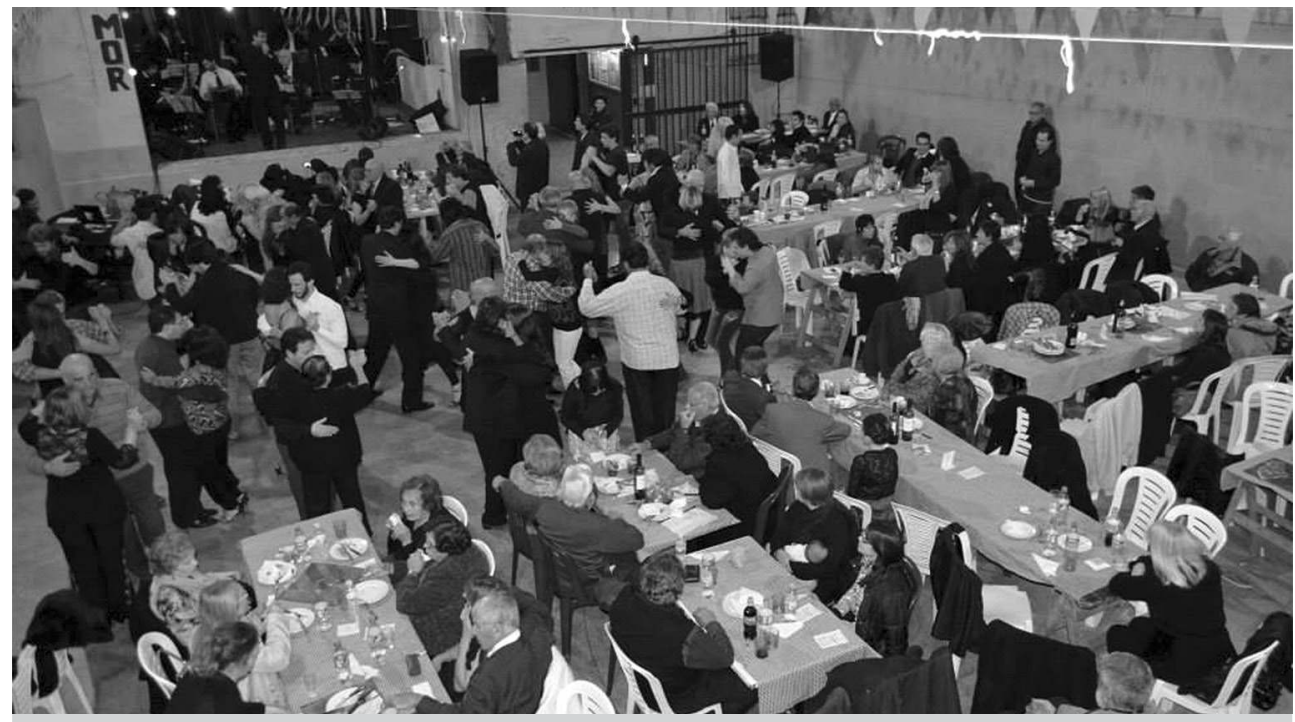

Figura 3 - La milonga del Morán (Foto: Hernán Morel).

Ambas milongas están organizadas por las mismas personas: Mariano Romero (quien además es también el musicalizador del evento), Marcelo Lavergat y Lucila Bardach. Un aspecto a destacar es que, a diferencia de lo que ocurre en el Sin Rumbo y el Sunderland, en el caso de estas nuevas milongas sus organizadores rondan entre los 30 a 40 años de edad, por lo cual pertenecen a una nueva camada de organizadores de milonga. Como veremos, a pesar de que estas milongas tienen algunas semejanzas con las milongas de Villa Urquiza, el hecho de que las organicen "jóvenes milongueros" implica algunas innovaciones y diferencias con respecto a las anteriores.

En principio, veamos el público al que buscan convocar los organizadores de estas milongas. Por un lado, la actividad que realizan estas milongas se publicita tanto por canales virtuales, a través del envío de correos electrónicos, Facebook y blogs, ${ }^{22}$ así como también realizan una difusión sin mediaciones, es decir, a través de afiches que pegan en las avenidas y calles de los barrios aledaños (ver figura 4). En el caso del Morán, estos afiches presentan a la milonga como "La fiesta popular del tango", apelando en su diseño gráfico a imágenes que incluyen banderines, lamparitas de colores, fileteados porteños y farolitos, a lo que se agrega en ocasiones fotos o imágenes antiguas. A su vez, en relación al público asistente señalemos que, dado que la milonga busca convocar en particular a los vecinos de la zona y a los milongueros locales, en estas nuevas milongas no se observa la participación de muchos turistas extranjeros, aunque suelen concurrir algunos. 


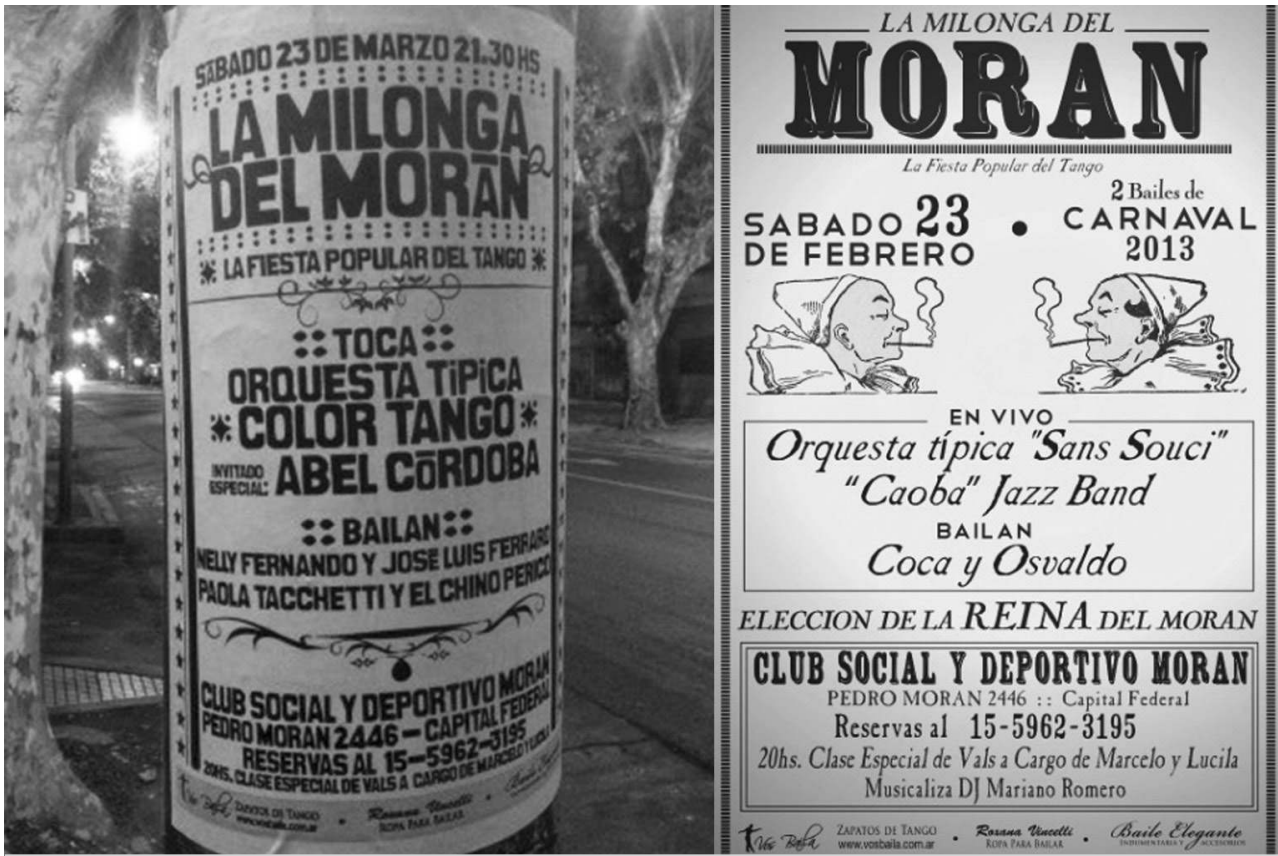

Figura 4 - Afiches que publicitan a la Milonga del Morán (Foto: Hernán Morel).

Podríamos decir que en estas milongas la organización del espacio interno es muy similar al de otras milongas de la zona, ello si tenemos en cuenta aspectos como el de la infraestructura, la iluminación, la ambientación, la distribución de las mesas o el espacio de la pista de baile. Sin embargo, en lo que refiere a las características de las personas que concurren, existen algunas diferencias significativas con las milongas de Villa Urquiza. En efecto, una crónica describe a la milonga del Morán del siguiente modo:

"Allí, no hay joyas, no hay gomina, no hay vestidos lentejuelados ni pañuelos que salen del bolsillo, ni corbata a tono con el atuendo de la dama, ni carteras brillantes ni charol impecable. En la Milonga del Morán, hay familias, hay niños, hay vecinos del barrio, hay pizza y cerveza, hay viejos que se duermen en su silla y jóvenes que se la pasan bailando en la pista de cemento sobre la cancha de fútbol, también hay el contrario, hay una vida increíblemente rica, abundante, múltiple, ruidosa y campechana". ${ }^{23}$

Advertimos a través de este relato una serie de imágenes asociadas a un conjunto heterogéneo y difuso de personas que participan del Morán, imágenes 
que se presentan en un claro contraste a la seriedad y la formalidad que suele prevalecer en las milongas que analizamos más arriba. En parte, la presencia de una mayor variedad en el promedio de edad de las personas, una franja generacional que transita de los 15 a los 80 años, colabora en que se modifiquen las dinámicas de sociabilidad y de comportamiento dentro de estos espacios. Al igual que lo señalado en el relato que describe a la milonga del Morán, muchos consideran que la vida social que allí se despliega tiende al logro de un ambiente menos normativo y regulado por determinados "códigos" fundamentales. Ello a diferencia del clima más solemne y "elegante" que caracteriza a las milongas de Villa Urquiza, en donde las personas y los grupos más establecidos y antiguos, quienes como vimos ocupan posiciones de prestigio y de poder, están atentos al respeto de estos "códigos".

Por otro lado, algo característico de estas nuevas milongas es que procuran "revivir" determinadas prácticas ligadas a un pasado significativo, inspirándose para ello en los comentarios de distintos vecinos y milongueros del barrio ${ }^{24}$ que suelen recordar los bailes que se realizaban en estos mismos clubes - el Morán y el Floreal - en las décadas del 40 y el 50. Destaquemos que son los mismos organizadores de estas milongas los que buscan "recuperar" estos elementos del pasado, elementos que, paradójicamente, habían sido dejados de poner en práctica por las milongas más "antiguas" de la zona. Afirma uno de los organizadores refiriéndose al Morán:

“'El club está a 10 cuadras de donde nací y me crié, por eso conozco bien el barrio - contó en charla con Télam Lavargata. Con Lucila, mi esposa, damos clases de tango en Villa Urquiza y Parque Chas desde hace tres años, y así surgieron las ganas de hacer una milonga por Agronomía, que convoque a los vecinos de barrios como Villa Pueyrredón, Saavedra, Villa Ortúzar, todos muy tangueros y que creo que forman una zona única en el mundo'. A partir de las charlas que mantuvieron con sus abuelos, con milongueros de antes y con los socios más antiguos del club, los organizadores fueron reconstruyendo una estética que hace que La Milonga del Morán se distinga del resto porque toma elementos de otros tiempos y las trae al presente". ${ }^{25}$

Ahora bien, ¿qué elementos "de otros tiempos" recuperan y "traen al presente" estos jóvenes organizadores? Por un lado, su propuesta incluye tanto un reconocimiento al legado cultural de los "más antiguos", aquellos "milongueros de antes", del mismo modo que también organizan distintas actividades

24 Por ejemplo, en el caso del Morán, la milonga posee un "padrino" representado en la figura de Eduardo Pareja, un reconocido milonguero y vecino del barrio, con más de 80 años de edad, el cual solía ir a bailar a este mismo club en sus años de juventud.

25 En < http://www.telam.com.ar/notas/201307/25092-la-milonga-del-moran-celebra-con-tango-vivo-barrial-y-popular.html >, 16 de julio de 2013 (última consulta en octubre 2016). 
que contemplan la participación de las nuevas generaciones, es decir aquellas personas y grupos que se han formado más recientemente. En virtud de ello suelen brindar exhibiciones de baile ${ }^{26}$ las nuevas camadas de bailarines profesionales y amateurs, a la par que frecuentemente se realizan "homenajes" con rondas de exhibición de baile o clases a cargo de los llamados "maestros/as" o "viejos/as" milongueros/as. A su vez, en el Morán otra práctica que recuperan "de las milongas de antes" consiste en realizar "bailes de carnaval" durante el caluroso febrero porteño. Para ello ambientan el club con una ornamentación especial para la ocasión, invitan a los asistentes a jugar a la "guerra de espuma", del mismo modo que organizan concursos de disfraces e instan a la elección de una "reina de carnaval". Además, en el Floreal, otra actividad que suelen realizar son concursos de baile en los que vota el público asistente, una práctica que también se inspira en los modos de evaluación que se utilizaban en los certámenes de las décadas del 40 y el 50.

Asimismo, los organizadores de estas milongas - particularmente en el Morán - incluyen en la programación del evento la actuación de orquestas o de distintas formaciones de tango ${ }^{27}$ - o de jazz - entendiendo que la presencia de los músicos en vivo era una práctica habitual en los "bailes de antes". Destaquemos que la presencia de orquestas y músicos en vivo tiene al menos dos implicancias. Por un lado, motiva la asistencia de un público nuevo que no necesariamente baila, me refiero a aquellos que van a mirar, a escuchar o que simplemente son seguidores del grupo o del artista que se presenta. Por otro, desde el punto de vista de los organizadores, esta mayor afluencia de público les asegura solventar los significativos costos adicionales que implica contratar a músicos en vivo.

En suma, vemos que al igual que en las milongas de Villa Urquiza, en estas nuevas milongas también se enfatizan determinados usos del pasado y de la tradición. Sin embargo, como fuimos señalando, los criterios de tradición que gobiernan a cada uno de estos lugares exacerban ciertos elementos como legítimos al mismo tiempo que prescinden de otros. En este contexto, los jóvenes organizadores plantean una mirada diferente del pasado asociado a las milongas barriales, apropiándose y poniendo en acto elementos de un pasado que los diferencia del que construyen otros (Jelin 2001). De manera que a través de

26 Se denomina "exhibición de baile" a una instancia de actuación previamente planificada por el organizador/a de la milonga. Esta actuación especial modifica e interrumpe con la actividad social del baile, en vistas a que una única pareja asume una puesta en acto ante la observación de los demás participantes de la milonga. Dicha pareja suele bailar dos, tres o cuatro piezas musicales, mientras el público observa sentado desde sus mesas. Luego de dar por terminada la exhibición, se vuelve al normal desarrollo de la práctica social del baile.

27 Entre las orquestas que se han presentado podemos mencionar a "Color Tango" o "Los Reyes del Tango", del mismo modo que han actuado cantores como Ariel Ardit, Guillermo Fernández o Cucuza Castiello, e incluso cantores de la época de oro del tango como Alberto Podestá o Carlos Godoy. 
estos distintos aspectos que retoman del pasado se establecen usos particulares y estratégicos del mismo. Así, si en el caso de las milongas que se realizan en Villa Urquiza se advierte un mayor dominio de los puntos de vista de los antiguos y más establecidos milongueros, en el caso de estas nuevas milongas estos puntos de vista están en mayor grado mediados por los sentidos que le dan al pasado los jóvenes organizadores. En efecto, este recambio generacional en los organizadores favorece la puesta en marcha de procesos novedosos en términos de los usos y las selecciones del pasado que se realizan.

\section{ALGUNAS REFLEXIONES FINALES}

Presenté hasta aquí algunas prácticas y dinámicas sociales que reconstruí durante mi trabajo de campo a través de mi participación cotidiana dentro un circuito de milongas que se organizan en clubes de la zona del noroeste de la ciudad de Buenos Aires. Para ello desarrollé un análisis comparativo y relacional (Bourdieu y Wacquant 1995; Barth 2000) en torno a cuatro milongas barriales que poseen tanto aspectos compartidos como diferentes entre sí. En principio, en todas estas milongas se construyen profundas tramas de relaciones sociales, basadas en el despliegue de ciertas formas de comportamiento, pautas de socialización e identificaciones con el lugar. Vimos que las milongas de Villa Urquiza detentan una autoridad sustentada en distintas narrativas que vinculan a estos lugares con determinadas memorias, personas destacadas y eventos significativos del pasado, hecho que contribuye a reforzar el carácter emblemáticamente tradicional de las mismas. A su vez, notamos que a través de la activación de determinados "códigos", normas específicas, estilos de baile distintivos - como el Villa Urquiza - y pautas ligadas a un pasado común, aquellos miembros y grupos más establecidos y antiguos tienden a rechazar otras formas de sociabilidad y de comportamiento que no se condicen con dichos "códigos" y restricciones.

Por su parte, el Morán y el Floreal, en tanto milongas que se reactivaron recientemente en los últimos años, no se perciben como lugares que capitalizan una trayectoria y una continuidad histórica como sí la visibilizan en mayor grado el Sunderland y el Sin Rumbo. Menos aún disfrutan de un relato "consagratorio" basado en los antiguos y "prestigiosos" milongueros que caminaron por sus pistas, del mismo modo que tampoco poseen su fama y repercusión internacional. No obstante, y a pesar de que son lugares menos conocidos y reconocidos dentro del mundo de los milongueros, éstos nuevos lugares de baile en sus pocos años de existencia han ido adquiriendo un importante poder de convocatoria, ampliando así el mapa de milongas que se realizan en los clubes de barrio de la zona. Lo interesante es que estas nuevas milongas también buscan posicionarse a través del empleo de la tradición como recurso, en este caso reinstaurando algunas "viejas prácticas" y actividades que habían sido 
olvidadas o dejadas de efectuar por otras milongas de la zona. Además, como vimos, tanto el Morán como el Floreal aspiran a ser eventos barriales y populares más abiertos e inclusivos, apelando para ello no solo al reconocimiento de los "viejos milongueros", sino también a partir de incentivar a que participen las nuevas generaciones y a que se incorporen los vecinos del barrio y de la zona. De algún modo, se podría afirmar que, al ser ámbitos sociales de formación más reciente, los lazos y las dinámicas de interacción que organizan a estas milongas obedecen menos al principio de permanencia y antigüedad que suele regir en otras milongas tradicionales de la zona.

Vimos también que esta renovación poblacional dentro de la milonga incide en el tipo de relaciones de poder e interacciones que se genera entre los participantes del evento, favoreciendo algunas formas de sociabilidad y pautas de comportamiento que podrían ser consideradas como más "relajadas" o que trastocan determinados "códigos" establecidos. En este sentido, advertimos cómo estos son lugares en donde personas con disímiles trayectorias, reputaciones y edades interactúan a partir de un menor grado de formalidad en el trato. Entre otros aspectos, allí se consiente y conviven tanto el uso de vestimentas "elegantes" como ropas de uso cotidiano; también se observan distintos estilos y niveles de baile, por lo que están aquellos que cultivan un baile más experto y profesional a la par de otros que recién están comenzando a bailar; así como la presencia de personas del mismo sexo bailando en pareja no suscita inconvenientes, como sí podría ocurrir en otras milongas tradicionales. De algún modo estos cambios emergentes son motorizados no solo a partir de la aparición de nuevos participantes que asisten a la milonga sino también a través de la renovación generacional de las personas que ofician como organizadores/as de estos eventos.

En síntesis, el crecimiento y la renovación en los últimos años en la cantidad de personas que bailan tango en estos lugares - a partir del arribo de generaciones de edad intermedia que antes no lo hacían, junto al incremento de los jóvenes y la aparición de nuevas camadas de organizadores de milongas parece estar reconfigurando las prácticas, los sentidos y las relaciones de poder que allí se despliegan. Principalmente, y a través del caso de algunas de las milongas barriales que funcionan en esta zona, intentamos reflexionar sobre las dinámicas de sociabilidad y las referencias al pasado singulares que poseen estos lugares. En particular, algo que nos interesó destacar es que inclusive en el caso de estas milongas en las que se ponderan tradiciones y elementos de un pasado significativo, estos también van reconfigurándose o adquieren nuevos significados en función de los nuevos contextos y agentes sociales que participan. De manera que el proceso de formación de sentidos en torno a estos lugares es consecuencia de las agencias y las interacciones de las personas y grupos que allí convergen, las cuales influyen en la emergencia de nuevas prácticas e interpretaciones. 


\section{BIBLIOGRAFÍA}

AUGÉ, Marc, 1993, Los “No Lugares”, Espacios de Anonimato: Una Antropología de la Sobremoderinidad. Barcelona, Gedisa.

BARTH, Fredrik, 2000, "Metodologias comparativas na análise dos dados antropológicos", en T. LASK (org.), O Guru, o Iniciador e Outras Variações Antropológicas. Rio de Janeiro, Contra Capa, 187-200.

BAUMAN, Richard, 2000, "Genre", Journal of Linguistic Anthropology, 9 (1): 81-84.

BOURDIEU, Pierre, y Loïc J.D. WACQUANT, 1995, "Pensar en términos relacionales”, en P. Bourdieu y L. Wacquant, Respuestas: Por Una Antropología Reflexiva. México, DF, Editorial Grijalbo, 167-175.

CAROzZI, María J., 2015, Aquí se Baila el Tango: Una Etnografía de las Milongas Porteñas. Buenos Aires, Siglo XXI.

CECCONI, Sofía, 2009, "Tango queer: territorio y performance de una apropiación divergente", Trans: Revista Transcultural de Música, 13, disponible en < http://www.sibetrans. com/trans/article/54/tango-queer-territorio-y-performance-de-una-apropiaci-n-divergente $>$ (última consulta en octubre del 2016).

CRESSWELL, Tim, 2004, Place: A Short Introduction. Malden, MA, Blackwell.

ELIAS, Norbert, 2000 [1994], "Introdução: ensaio teórico sobre as relações establecidos-outsiders", en N. Elias y J.L. Scotson, Os Estabelecidos e os Outsiders: Sociologia das Relaçães de Poder a partir de Uma Pequena Comunidade. Rio de Janeiro, Jorge Zahar Editor, 19-50.

GONÇALVES, Renata de Sá, 2013, "Eu sou o samba: sobre lugares, pessoas e pertencimento", Sociedad e Cultura, 16 (1): 105-115.

GUPTA, Akhil, y James FERGUSON, 2008, “Más allá de la 'cultura': espacio, identidad y las políticas de la diferencia”, Revista Antípoda, 7: 233-256.

JELIN, Elizabeth, 2001, “Transmisiones, herencias y aprendizajes”, en E. Jelin, Los Trabajos de la Memoria. Madrid, Siglo XXI, 117-133.

LISKA, María Mercedes, 2009, "El tango como disciplinador de cuerpos ilegítimos-legitimados", Trans: Revista Transcultural de Música, 13, disponible en < http://www.sibetrans. com/trans/articulo/53/el-tango-como-disciplinador-de-cuerpos-ilegitimos-legitimados > (última consulta en octubre del 2016).

LUCIO, Mayra, y Marcela MONTENEGRO, 2012, "Ideologías en movimiento: nuevas modalidades del tango-danza”, en S. Citro y P. Ascheri (coords.), Cuerpos en Movimiento: Antropología de y desde las Danzas. Buenos Aires, Editorial Biblios, 201-218.

MARTÍN, Alicia, 2005, "Introducción”, en A. Martín (coord.), Folklore en las Grandes Ciudades: Arte Popular, Identidad y Cultura. Buenos Aires, Libros del Zorzal, 7-16.

MOREL, Hernán, 2011, "Estilos de baile en el tango salón: una aproximación a través de sus evaluaciones verbales", en M.J. Carozzi (coord.), Las Palabras y los Pasos: Etnografías de la Danza en la Ciudad. Buenos Aires, Gorla, 189-222.

MOREL, Hernán, 2012, “Vuelve el tango: ‘tango argentino' y las narrativas sobre el resurgimiento del baile en Buenos Aires", Revista del Museo de Antropología, 5: 77-88.

OCHS, Elinor, 2000 [1997], "Narrativa”, en T. Van Dijk (coord.), El Discurso como Estructura y Proceso: Estudios del Discurso: Una Introducción Multidisciplinaria. Barcelona, Gedisa, 27 1$-303$.

PEIRANO, Mariza, 1995, A Favor da Etnografía. Rio de Janeiro, Relume-Dumará. 
PUJOL, Sergio, 1999, Historia del Baile. Buenos Aires, Emecé.

RAMOS, Alejandra, 2008/2010, "El mundo de la milonga y las estrategias actuales de legitimación del tango", Cuadernos del Instituto Nacional de Antropología y Pensamiento Latinoamericano, 22: 191-202.

SAHLINS, Marshall, 2004, "Adeus aos Tristes Tropos: a etnografia no contexto da moderna história mundial", en M. Sahlins, Cultura na Prática. Rio de Janeiro, Editora da UFRJ, 503-534.

SAVIGLIANO, Marta, 2002, "Jugándose la femineidad en los clubes de tango de Buenos Aires", Guaraguao: Revista de Cultura Latinoamericana, 15: 68-101.

TRAJANO FILHO, Wilson, 2012, "Introdução”, en W. Trajano Filho (coord.), Lugares, Pessoas e Grupos: As Lógicas do Pertencimento em Perspectiva Internacional. Brasília, ABA Publicações, 7-26.

WILLIAMS, Raymond, 2000 [1977], “Tradiciones, instituciones y formaciones", en R. Williams, Marxismo y Literatura. Barcelona, Península, 137-150. 